Journal of Patient-Centered

Volume 4

Issue 4 -- Health Disparities and Inequities: Part

Article 20 I

$11-6-2017$

\title{
The Lifestyle Initiative: An Innovative Coaching-Based Quality Improvement Study to Improve the Health of Aurora Health Care Caregivers and Family Members
}

Tiffany A. Mullen Jessica J.F. Kram

Dennis J. Baumgardner

Follow this and additional works at: https://aah.org/jpcrr

Part of the Community Health and Preventive Medicine Commons, Dietetics and Clinical Nutrition Commons, Endocrinology, Diabetes, and Metabolism Commons, Family Medicine Commons, Health Services Administration Commons, Integrative Medicine Commons, and the Public Health Education and Promotion Commons

\section{Recommended Citation}

Mullen TA, Kram JJ, Baumgardner DJ. The Lifestyle Initiative: an innovative coaching-based quality improvement study to improve the health of Aurora Health Care caregivers and family members. J Patient Cent Res Rev. 2017;4:260.

Published quarterly by Midwest-based health system Advocate Aurora Health and indexed in PubMed Central, the Journal of Patient-Centered Research and Reviews (JPCRR) is an open access, peer-reviewed medical journal focused on disseminating scholarly works devoted to improving patient-centered care practices, health outcomes, and the patient experience. 
for patient characteristics, device specifications and indicators of post-THA complication (serum $\mathrm{Cr}$ ion, Co ion, C-reactive protein, erythrocyte sedimentation rate).

Results: In total, 162 hips and 152 unique patients underwent THA during September 2009-May 2012, with 78 hips subsequently revised during 2012-2015. Patients were of median age 62 years (range: $32-$ $90)$, nearly all non-Hispanic white (89\%) and mostly female (58\%). Several variables were significantly associated $(\mathrm{P}<0.05)$ with ALTR grade, including occurrence of complication symptoms (eg, pain), patient age, and Co ion concentrations. Revision surgery was the most strongly associated variable with ALTR, with 5 times greater odds of abnormal grade when not undergoing revision (odds ratio: 5.68, 95\% confidence interval: 2.69-11.9).

Conclusion: Within AHC, patients who underwent THA with the Stryker Rejuvenate hip implant often experienced the complications of ALTR, but revision surgery reduced the ALTR grade.

\section{Family Practice Resident Expectations by Year From Faculty and Resident Perspectives: A Quality Improvement Initiative}

Alyssa Krueger, Devin Lee, Jessica J.F. Kram, Will Lehmann, Dennis J. Baumgardner

Department of Family Medicine, Aurora University of Wisconsin Medical Group; Center for Urban Population Health

Background: The transition from student to physician requires substantial commitment and work from residents as well as guidance from program faculty. The Accreditation Council for Graduate Medical Education (ACGME) has standardized certain academic requirements for U.S. residency programs; however, faculty expectations of residents according to year in the program are less formal and more a hidden curriculum. Setting expectations for residents to consult could better help residents navigate their graduate medical education experience and achieve the level of excellence expected by ACGME. Purpose: Our quality improvement study aimed to: 1) determine what the expectations of family practice residents were based on feedback from faculty members and current residents; and 2) share these expectations with residents.

Methods: A preintervention survey was emailed to family medicine program faculty and residents regarding resident expectations according to year in the program. Based on the results of the preintervention survey, expectations were outlined in a handout according to year in the program and were presented to current residents during scheduled didactic time. Residents who responded to the preintervention survey were then asked to respond to the postintervention survey. Fisher exact tests were used to compare preand postintervention survey responses.

Results: Overall, 64\% (14 of 22) of faculty and 64\% (18 of 28) of residents responded to the preintervention survey. While $79 \%$ of faculty expressed that they had specific expectations for residents, $77 \%$ felt that residents did not know these expectations. Additionally, while residents (94\%) believed faculty had expectations of them, only $33 \%$ knew what the expectations were. Following intervention, 15 of 18 residents responded, with $79 \%$ now reporting they knew what the expectations were $(\mathrm{P}=0.02)$. The handout was found useful by all those queried, and $85 \%$ felt it clarified expectations.

Conclusion: At baseline, residents and faculty knew there were expectations for residents as they progress through the program, but those expectations were not explicit. Despite the lack of vertical communication, the expectations from both groups were surprisingly similar. A handout delivered electronically and at didactic sessions was deemed useful and clarified expectations.

The Lifestyle Initiative: An Innovative Coaching-Based Quality Improvement Study to Improve the Health of Aurora Health Care Caregivers and Family Members

\author{
Tiffany Mullen, Jessica J.F. Kram, Dennis J. Baumgardner
}

Department of Integrative Medicine, Aurora Sinai Medical Center; Department of Family Medicine, Aurora University of Wisconsin Medical Group; Center for Urban Population Health

Background: Self-management support has been shown to improve clinical outcomes. Health coaching, one form of self-management support, empowers patients within the health care system by providing information and through collaboratively developed care plans.

Purpose: Assess the impact of The Lifestyle Initiative, a coachingbased health program utilized by Aurora Health Care caregivers or family members.

Methods: The Lifestyle Initiative is a coaching-based approach for Aurora caregivers or family members enrolled in Aurora's health insurance network. Individuals were recruited from the care management database, and all participants had an Aurora primary care provider. Participation was limited to those $\geq 18$ years of age who had a diagnosis of type 2 diabetes or hypertension (or both), had glycated hemoglobin $(\mathrm{A} 1 \mathrm{c}) \leq 8.0$, and were not on insulin. The Lifestyle Initiative was rolled out in three phases. Phase I: health coaching sessions through a standard web- and app-based platform (Noom Health), and access to a stress-management program (HeartMath). Phase II: health coaching sessions through a standard web- and app-based platform co-created by Aurora's Department of Integrative Medicine and Noom Health, and access to HeartMath; Phase III: health coaching sessions through a standard web- and app-based platform (Noom Health), and a customized web- and app-based platform. Those enrolled in each phase acted as their own controls. Paired t-tests were used to compare pre- and postintervention results of each phase.

Results: The majority of Phase I participants ( $\mathrm{n}=23$; mean age 54.4 years) were female $(91.3 \%)$ and white $(52.2 \%)$. Preintervention A1c and blood pressure were not statistically different postintervention. However, pre- vs postintervention weights were statistically different (228.2 vs $218.5 \mathrm{lb} ; \mathrm{P}<0.01$ ), as well as pre- vs postintervention body mass index ( 37.3 vs $\left.35.7 \mathrm{~kg} / \mathrm{m}^{2} ; \mathrm{P}<0.01\right)$. The majority of Phase II participants $(\mathrm{n}=63$; mean age 54.8 years) also were female $(81.0 \%)$ and white $(88.9 \%)$. Pre- and postintervention blood pressures were not statistically different. However, pre- vs postintervention A1c (7.2 vs 6.6; $\mathrm{P}<0.02$ ), weights ( 229.6 vs $225.7 \mathrm{lb} ; \mathrm{P}<0.05$ ), and body mass index ( 37.1 vs $36.5 \mathrm{~kg} / \mathrm{m}^{2} ; \mathrm{P}<0.05$ ) were statistically improved. Phase III data collection is underway.

Conclusion: The Lifestyle Initiative health coaching program significantly improves certain health metrics when applied to health system employees and family members with diabetes or hypertension. Further study is needed to explore sustainability and the effects of more robust programs.

Improving Obstetrics in Family Medicine Residency Clinics: A Quality Improvement Study

Garima Chawla, Jessica J.F. Kram, Bonnie Bobot, Dennis J. Baumgardner

Department of Family Medicine, Aurora University of Wisconsin Medical Group; Center for Urban Population Health 